\title{
Manipulative Leadership and The Effect towards Its Subordinate as Portrayed in Orson Scott Card's Novel
}

\author{
Sharavina Delani \\ English Literature Department \\ Universitas Ahmad Dahlan, Yogyakarta \\ sharavinadelani@gmail.com
}

\begin{abstract}
Article Info
ABSTRACT

Article History

- Article Received

$3^{\text {rd }}$ February 2019

- Article Reviewed

$5^{\text {th }}$ February 2019

- Article Accepted

$7^{\text {th }}$ March 2019

\section{Keywords}

american cultural

values

leadership

manipulative

styling

popular culture

Literary works, such as novel, usually comes from the writer's feeling; it could be the feeling of love, frustrations, angers, satisfactions, disappointments, satire, and many other feelings towards an individual, social, organizations, even the government. A novel could also be some kind of warning towards the readers so that they could be cautious if there are any similar events happen in their real life. The main objective of this research explains the American manipulative leadership and the American cultural values seen in Ender's Game and to analyze the effect of American Manipulative Leadership towards its Subordinate shows by Ender's Game. The researcher uses the qualitative method to analyze the primary data and the supporting data using content analysis to interpret the images, symbols, and words.

This undergraduate thesis concludes two major points. Firstly, American manipulative leadership uses two values; which are risk-taking and the future, change, and progress and forgotten two other values, directness/openness/honesty and freedom of American Cultural values. Secondly, American manipulative leaderships also affect the subordinate psychological condition. And novel can also be called as a popular culture due to its enormous achievement and its consumption by the mass.
\end{abstract}

\section{INTRODUCTION}

In discussing American Studies there are important things that need to be better understood about the United States of America (USA). This is because the USA is known as the center of much information, in the fields of culture, sport, automotive, technology, economics, politics, information and communication, military systems and also entertainment. All these occur because the Americans believe in and hold on to their American Dream. Everyone is able to acquire their success as long as they hold on to their aspirations and apply the principle of the American Dream which contributes a substantial amount of hope that every American will have an equal opportunity to achieve success through sweat, patience, and endeavor.

It includes film, corporation, literary works, and others. One of the spheres that exists in the literary worlds is popular literature. The distinguishing characteristics of popular literature are the methods and the aims of the authors in creating the work. People often say that the reason that someone creates such a literary work is to express him or herself. It could be the expression of a lot of things, such as happiness, sadness, love, hate, satisfaction, disappointment, loyalty, betrayal and other feelings that the researcher experiences.

A story about a war is a common thing to write now, and usually influenced by the past and the 
current events. The war hero is what the readers want. In order to find and make a great commander in the field, the chief in command must do some things that might not sound appropriate, but that need to be done. These not so appropriate acts are usually called 'moral lapses' and include lying and withholding information. When reaching the goals, either it is in the field or in the office, the Americans are grasping at the concept of the American Dream. Hochschild[1] stated that "the American dream consists of tenets about achieving success" (p. 15). At the time that concept or American Dream is being use a standard where everyone can achieve success, the values of America are also being use by the Americans to achieve their purpose.

But, according to Cullen[2], "Many Americans, disappointed if not appalled by such hucksterism and laziness, fear that the once-grandiloquent cadences of the Declaration are now empty slogans and that the American Dream has lost its luster and may even be dying. But this novel shows that these American Dream principles and the values that the American life by are still needed and used to achieve the success even though the methods of gaining the goal sometimes deviate from the moral values for as long as it is for a good purpose, even though this is considered as abuse of power.

An example of an act of abuse of power was the issue of "Richard Nixon's Plumbers". Although Nixon denied knowledge of the Plumbers' activities, tapes subpoenaed during the Watergate investigation revealed years of political espionage and illegal surveillance. The "Smoking Gun" tape revealed that Nixon was involved in the cover up[3]. This is an example of the misuse of power but the purpose of it is for personal gain.

Through this research, the researcher hopes that by analyzing this subject, people can see that manipulative leadership is sometimes not as bad as it sounds. This act often needs to be done because not all people understand the necessity of manipulative leadership. People cannot only see it from the definition of 'manipulate', 1) control or influencing somebody/something, especially in a dishonest way, 2) control or use something in a skillful way[4]. The 'dishonest' way is something that shows that American values are starting to fade.

This undergraduate paper examines the American manipulative leadership characteristics of the main character superior in Ender's Game by using cultural and social approach. The scope of study is limited to analyzing this manipulative leadership and the effect on its subordinates, specifically in Ender's Game by Orson Scott Card.

\section{LITERATURE REVIEW}

In order to achieve valid results in this research, the researcher uses the American studies discipline by Meredith[5]. "American studies is an interdisciplinary which utilizes social scene, literature, history, politics, economic structure, etc." In the American studies program, these theories are used as guidance in writing this undergraduate thesis. As the research is interdisciplinary, multidisciplinary approaches have to be used to get a deep understanding about American Studies.

In this study, the researcher uses the cultural and social approach. Borrowing from Storey [6], Raymond Williams[14] suggest that culture used to refer to 'a general process of intellectual, spiritual, and aesthetic development' (87). Cultural theory is used to analyze the cultural values of America that cannot be separated from the American culture such as Freedom, Directness/Openness/Honesty, and Changing the Future. The next approach is Popular Culture. "An obvious starting point in any attempt to define popular culture is to say that popular culture is simply culture that is widely favored or well-liked by many people. And, undoubtedly, such a quantitative index would meet the approval of many people" [6]. To analyze the manipulative leadership in Ender's Game, social approach is used. Leadership will be used in society, whether it is a small or even a big society. Borrowing from Northouse[7] in 1960 the prevailing definition of leadership as behavior that influences people toward shared goals was underscored by Seeman (1960) who described leadership as "acts by persons which influence other persons in a shared direction" (p. 53).

Ender's Game is a popular novel by Card where he pours out all the ideas stuck in his mind from when he was just a boy. Using his brother's experiences in the military he wrote a science fiction novel, like the ones he used to read. The way he portrays a manipulative lying superior is what makes the story interesting to read. Thus the reason why this novel comes to be the main source of the thesis and how subordinates are affected by a manipulative leader. 
Social theory in the base of the individual's goaldirected behavior which is taken in specific institutional and structural setting which molds the motivations and the actions of thus made a possible link between the individual and society, and it even builds the construction of how the systems of the social might be molded by human will. Quoted from Elliot, "In contemporary social theory, certain core themes take precedence over others, themes such as the nature of social life, the relationship between self and society, the structure of social institutions, the role and possibility of social transformation, as well as themes such as gender, race and class". Briefly, the particular purpose set by the individual about to create connection between the person and the society which could be the form of social systems because of human volition. In contemporary social theory, some central subjects are more important than other subjects, such as the establishment of social structure, self and society's relationship, and the social shifts of action and possible action, including leadership.

American is known for their obsession to hold power over the world. America wanted to be the leader who has the power to control the world and be the most powerful nation on earth. Therefore, any ways will be used by the Americans. Those ways are sometimes genuine, but often also immoderate.

Adopting from Jacobs et al, McCormack (1992) "seeks to advance a theory that is sensitive to the 'extremely subtle shading information' that can occur in deception and that captures the Important distinctions in the (combination of) ways that information is manipulated".

Some information is concealed in a very careful way which makes it very difficult to grasp. Because of that matter, people given the Information usually believe the information without a doubt. Those who give information hide the truth of the information so that others can be manipulated with its lies. In order to detect a manipulative leader, Maxwell[8] offers three tactics of a manipulative leader. First, they misuse or abuse power. Having a positional advantage over their followers, leaders generally

enjoy their position. It means that they can mete out a punishment and issue a reward, because they have the dominance. The abuse of power is commonly done to ensure personal advantages and to raise their own prestige.
Second, they fabricate or withhold information. Misinformation is used by leaders to manipulate people. Manipulation not only happen in financial shams, but also in corporations and government. Leaders may plainly mislead their components by emphasizing the positives of an arrangement while concealing the drawbacks.

Third, manipulative leaders prey on the emotions of others. Manipulative leaders mostly are not blind to the other needs. As a matter of fact, the most delusory leaders are keenly aware of the aspirations and wants of their people, and they use this cognition to control others. To grow their charm, they appeal to hopes and fears while downplaying reasoning and logic.

Concisely, leaders who are too comfortable with their position over others tend to use their power to take advantage of it for the gain of themselves. Manipulative leaders usually are good at hiding the right information and replacing it with a shading and made-up information. Manipulative leaders tend to abuse their power, withholding information, and target the others emotions.

\section{METHODOLOGY}

The method used in the research is library-type of research. In a book entitled How to Write a Thesis, 3rd ed., "It is called library-type of research which requires a search of written materials" [9].

In this research, the main source of the data is taken from Ender's Game by Orson Scott Card consisting of 17 chapters, including the Acknowledgment and Introduction with 368 pages in total. Every chapter and dialogue in the novel reflect the American manipulative leadership in the novel. The supporting data is taken from various sources like articles, biographies, literary books, research and other materials related to analysis of the novel and related topics. The data will support the main data.

In analyzing the data, there are two kinds of techniques, namely qualitative and quantitative analysis. The researcher uses the descriptive qualitative methods to analyze the data from the resources. It starts by reading the novel and continues by exploring the storyline. Comprehending the story is essential because the researcher must be aware of the characters and the events happening around the character. 
Crossman[10] offered qualitative method look into interpretations, meanings, symbols, and the processes and connection of social life. Qualitative method produces descriptive data that uses stringent and systematic methods of coding, transcribing, and analysis of themes and trends which then must be interpreted by the researcher. Bogdan and Biklen[11] also add that one of the characteristics of qualitative method is description. Descriptive technique is the interpretation of the content and arranges systematically to describe the main data that deals with the object.

In order to achieve valid results in this research, the researcher uses the American studies discipline by[5]. "American studies is an interdisciplinary which utilizes social scene, literature, history, politics, economic structure, etc." In the American studies program, these theories are used as guidance in writing this undergraduate thesis. As the research is interdisciplinary, multidisciplinary approaches have to be used to get a deep understanding about American Studies.

In this study, the researcher uses the cultural and social approach. Borrowing from Storey[6], Raymond Williams[14] suggest that culture used to refer to 'a general process of intellectual, spiritual, and aesthetic development'. Cultural theory is used to analyze the cultural values of America that cannot be separated from the American culture such as Freedom, Directness/Openness/Honesty, and Changing the Future. The next approach is Popular Culture. "An obvious starting point in any attempt to define popular culture is to say that popular culture is simply culture that is widely favored or well-liked by many people. And, undoubtedly, such a quantitative index would meet the approval of many people"[6]. To analyze the manipulative leadership in Ender's Game, social approach is used. Leadership will be used in society, whether it is a small or even a big society. Borrowing from Northouse[7] in 1960 the prevailing definition of leadership as behavior that influences people toward shared goals was underscored by Seeman (1960) who described leadership as "acts by persons which influence other persons in a shared direction".

Ender's Game is a popular novel by Card where he pours out all the ideas stuck in his mind from when he was just a boy. Using his brother's experiences in the military he wrote a science fiction novel, like the ones he used to read. The way he portrays a manipulative lying superior is what makes the story interesting to read. Thus the reason why this novel comes to be the main source of the thesis and how subordinates are affected by a manipulative leader.

\section{RESULT AND DISCUSSION}

\section{a. Manipulative Leadership found in Ender's Game}

In every society, there are always going to be a leader. It does not have to be labeled as a leader, sometimes it just that person who has the ability to guide and move the society. A leader not only have to think about his or her needs and desires, but also to think of the demands and wants from his or her followers and for the good of others. A leader that would do anything for the purpose of his or her self is commonly called as a manipulative leader. As mentioned in the last chapter, there are three tactics of manipulative leaders[8]. First, they misuse or abuse power. Second, they fabricate or withhold information. Third, manipulative leaders prey on the emotions of others.

Ender grabbed Mazer's uniform and hung onto it, pulling him down so they were face to face. "I didn't want to kill them all. I didn't want to kill anybody! I'm not a killer! You didn't want me, you bastards, you wanted Peter, but you made me do it, you tricked me into it!" He was crying. He was out of control.

"Of course we tricked you into it. That's the whole point," said Graff. "It had to be a trick or you couldn't have done it. It's the bind we were in. We had to have a commander with so much empathy that he would think like the buggers, understand them and anticipate them. So much compassion that he could win the love of his underlings and work with them like a perfect machine, as perfect as the buggers. But somebody with that much compassion could never be the killer we needed. Could never go into battle willing to win at all costs. If you knew, you couldn't do it. If you were the kind of person who would do it even if you knew, you could never have understood the buggers well enough." (Source: Card, Ender's Game, page 298)

Graff and Rackham both shows the three tactics proposed by Maxwell that would use by manipulative leaders. They abuse their power to gain their own purpose to win the war against the Formic using Ender as their 'secret weapon'. They also fabricate the information by telling Ender that that day is the examination day where he has to do his battle graduation. Graff and Rackham also preys and plays on Ender's emotions so that he is willing to fights the 
war against the Formic, win it, and end it once and for all.

Manipulative leadership not only affect the individual around the leader, but also the whole society, corporation, and government. The dialogue demonstrates the effect of the manipulative leadership, particularly towards the individual subordinate. But, the moment Graff and Rackham fabricate the true information, they also cover up the truth. At the time Ender know the whole truth and the effects of his actions in the graduation battle, the truths affect his mental condition. He thought that he is a killer now. He feels that he would be remembered forever as a murderer because the genocide the he does towards the Formic. By destroying their planet, it means that he is not only killing the queen, but also killing the entire Formic.

"We had pilots with our ships, didn't we."

"Yes."

"I was ordering pilots to go in and die and I didn't even know it."

"They knew it, Ender, and they went anyway. They knew what it was for."

"You never asked me! You never told me the truth about anything!"

"You had to be a weapon, Ender. Like a gun, like the Little Doctor, functioning perfectly but not knowing

what you were aimed at. We aimed you. We're responsible. If there was something wrong, we did it."

(Source: Card, Ender's Game, page 298)

Ender feels that he was not merely kills an entire species of the Formic, he kills his fighters and pilots in the ships as well. Ender senses that he is not the hero but the killer. He is not the protagonist here, but the antagonist that destroyed everyone that bothers and make a mess with him. With the manipulative leadership style that Graff and Rackham use, they really put a number on Ender's psychological condition. They not exactly thought about the effects of their manipulative leadership as long as they win the war against the Formic and put an end to it.

That case tells that Graff and Rackham only thought about the winning, but Ender feels that it is not only about the winning, the way they win matters. It shows that Graff and Rackham take Ender's liberty to acknowledge the truth and also take away the essential of human freedoms from Ender. Those indicates that when manipulative leadership style is being use, it is not only vanishing the values of the American live by, but also causing an effects towards the subordinate, such as confusing the subordinate and affecting the psychological condition of the subordinate.

As mentioned before, manipulative leadership uses three tactics when using this type of leadership. Those are; the abuse of power, withholding information, and preying on the emotions of others. While doing these three tactics, the leader is also breaking some American Cultural Values. The breaking of some values are not supposed to be done because when the leader is breaking those values it would also means that the leaders are starting to forgotten the values of the nations which then effect the identity of the nation.

As already mentioned in the previous chapter, because people of America come from all over the place, the cultures exhibited by the Americans also comes from all over. The belief that the New World is for everyone becomes the nature of the American Dream. To achieve their dream the Americans are also grasping on the American cultural values. In order to achieved their dream, there are going to be a lot of ways to get there. But, sometimes people are not only using the proper ways but also any sort of ways that maybe out of the logical reasoning.

\section{b. A Case find in Ender's Game that Contradict the American Cultural Values}

1) The Loss of Directness/Honesty

In the previous chapter that the writer has already mentioned, Americans are known for their directness towards other people about what they think and what the feel. But, these kind of value does not appear in this novel, Ender's Game.

The monitor lady smiled very nicely and tousled his hair and said, "Andrew, I suppose by now you're just absolutely sick of having that horrid monitor. Well, I have good news for you. That monitor is going to come out today. We're going to just take it right out, and it won't hurt a bit."

Ender nodded. It was a lie, of course, that it wouldn't hurt a bit. But since adults always said it when it was going to hurt, he could count on that statement as an accurate prediction of the future. (Source: Card, Ender's Game, page 2)

The dialogue proves that the values that people attribute to that the Americans as direct and honest people is not true. Many people said that Americans more likely talk straight to the point. But not this value, this dialogue shows that the Americans also talk 
some nonsense and say things that contradict with the truth. This proves that the honesty by the Americans is starting to fade. The values of openness, directness, or honesty is beginning to be forgotten by the Americans themselves. Ender's easily understands that the monitor lady only talking about some crap. The logical thought of Ender contradicts what the monitor lady says. He knows that the process of taking out the monitor was not going to hurt a bit, but it was going to hurt, a lot.

People do not always say what they think and what they want to say to other people bluntly. People are often like to tell some lies to others. Americans do talk nonsense and lie to other people, even those who have a higher position and those who live longer. But the people who are being lie to sometimes can read that lie right beforehand, including those who have a lower positions and a less experience of life. In the end, the small portion of narration appears to attest that those beliefs saying that the Americans are a direct, open and honest people are not exactly true.

\section{2) The Lack of Freedom}

Freedom is every human's rights. Humans are supposed to have their own freedom to do anything they like without any limit, as long as it is set aside with the norm taking place in the environment. Those freedoms include their liberty to do anything as they please without any interference from the government or other organizations. The belief to have their own freedom is so precious to the Americans with their long historical background coming out from their land they were born to come to America so that they have their freedom of speech or expression, freedom of beliefs, freedom from the desire to take over the world, and the freedom from fear of other nations.

"I've watched through his eyes, I've listened through his ears, and tell you he's the one. Or at least as close as we're going to get."

(Source: Card, Ender's Game, page 1)

When the Americans treasures their freedom, the dialogue shows that they don't actually have their liberty. The government, especially the military, is watching every second of Ender's life. They watch everything happen in his life, right through his eyes. Not only that, they also listen to every conversation and voices that he hears and take place around him through his ears. This means that the Americans do not have the kind of freedom they think they have.
The loss of liberty shows that essential human freedoms presented and desirable by Franklin D. Roosevelt[13] were not recognized by the government here after. One of four freedoms delivered by the thirty second president of the United States of America is "Freedom from fear." The last freedom translates as the freedom from feeling any fear of other nation. This last freedom proposed by FDR refers to the longing of people about others nations possession and actions. The dialogue presented above sort of makes it feel that the government afraid of the actions of other countries but in addition to that, they are also afraid of their own society.

The dialogue given show that the government beginning to narrow the freedom of every person. They believe that they are doing it for the the good of the nation so that there are no actions taken or planned by the citizens that are going to harm the nation. Though the intention of the government is for the sake of the nation, those actions cannot be tolerated because it distorts what the New World offers the first time around. The New World is notoriously known as the land of freedom from the first comers. The USA is afterwards known for their liberty by the following immigrant. On the other hand, the dialogue above indicates that the government starting to limiting the freedom of society. This lack of freedom contradicts with the values of the America toward its society.

\section{c. Grasping the American Cultural Values in Manipulative Leadership shown in Ender's Game}

1) The American Cultural Values in Manipulative Leadership shown in Ender's Game

In living their lives, Americans take hold of their values. Seeking freedom and opportunities, a group of people from England risked their lives to make the first settlement of the New World. Their view to see the unknown land as a place to set their future became one of the value to make their American Dream. Those voyagers were taking the risk to sail to the other side of the world, even though the risk of making it alive was less than fifty percent. That risk was taken so that they could have a better future. Although, nowadays, there are some values that are starting to fade and become forgotten by the Americans, there are still other values which still valued by the Americans. Though these were not believed by all the Americans, those values were still suits their basis in achieving their American Dream. Some values are still 
uses as one of the motivation the American reaching their ambition for a better future.

a) American as a Risk-Taking

As previously mentioned in the last chapter, people are going to faces so many choices in their lives. Choices also come with the risk after the choices taken. Risk-taking becomes a part of choices and cannot be separated from life. The consequences coming from the choices can type as a simple and a complicated consequence. Risk-taking is also has the almost same principle. The difference is, a simple or a complicated risk-taking comes with either simple or complicated result. It depends on the choices made by the person and the effect of that choice on his or her life.

Then he whispered a command and the ships dropped like rocks toward the planet's surface. They were starships and fighters, completely unequipped to handle the heat of passage through an atmosphere. But Ender never intended them to reach the atmosphere. Almost from the moment they began to drop, they were focusing their Little Doctors on one thing only. The planet itself.

One, two, four, seven of his fighters were blown away. It was all a gamble now, whether any of his ships would survive long enough to get in range. It would not take long, once they could focus on the planet's surface. Just a moment with Dr. Device, that's all I want. It occurred to Ender that perhaps the computer wasn't even equipped to show what would happen to a planet if the Little Doctor attacked it. What will I do then, shout Bang, you're dead?

\section{(Source: Card, Ender's Game, page 294-295)}

Ender is taking a risk to come forward approaching the enemy planet. He knows that it is impossible if all of his members of the fleet would survive the battle when they came near the enemy territory. He knows the risk and he trusts his squadron members that they have their loyalty to him. He has to take that risk to accomplish his success, especially if it relates with the public, national security, and continuance life of people on earth.

All of the proves above showed that in order to get what a person want to get, there is going to be a risk that has to be face. It is better if people just confront the risk directly, because if it is what the people want then it is worth it. Taking a risk would not be always pointed to the success that that person want, if it is ends in a failure, then learn from that failure in days to come. Failure is a process, better to fail than not to try because the only failure is not to try. So, taking a risk would establish the people whether they are courageous enough to take a risk to achieve their success.

\section{b) American viewed about The Future, Change, and Progress}

People believes that the Americans are not only thinking about things right in front of them, but also thought about things a hundred feet ahead. Americans believes that the past is not that really count, what matter is the future. Though the past and the present are not entirely what they wanted, they are battling for their future. Americans do not believe with the impossible, they confront the impossible. They believe that everything is possible, only, it would be harder to get and need more hard work than the ordinary.

\section{d. Ender's Game as a Popular Culture}

Not only do the narratives of the story recognize by the readers, but also the proves of the awards and reviews that come out from Ender's Game that make it popular. The popularity of Ender's Game also proves by the awards that come with it. Ender's Game awarded with the Nebula and Hugo awards in the year of 1985. The popularity of Ender's Game is incredible, it shows with its great achievement, though after almost 30 years of the first publication in 1985, in the week of June 09, 2013 Ender's Game is \#1 in the Paperback Mass-Market Fiction after 32 weeks on the list of The New York Times. And when it is just a new comer of the list of Paperback Trade Fiction, it comes straight up to \#16 on the week of August 4, 2013.With proves given above, the novel of Ender's Game can be categorizes as a popular culture, because its achievement are really great and it became a mass consumption since the mass are really fond of it.

\section{CONCLUSION}

The analyze of the novel produce the outcome of the American values uses by the leaders of America and the type of manipulative leader that often use by some leader in America.

First, the American Manipulative Leaderships which Graff and Rackham do, already left out the values the American live by. The loss of the value of directness or honesty and the lack of freedom found in the novel of Ender's Game. In the present days 
these two values are also starting to fade. Values is one of the important thing to shape a nation, and when the values are starting to fade, then the identity of the nations is also beginning to disappears. Though in the object of the studies and in the real world the researcher found the loss of Directness/Honesty and the lack of Freedom in Manipulative Leadership style, two other values are still uses as a guide in living everyday life. Those values are Risk-Taking and The Future, Change, and Progress. The research proves that the American Manipulative leader apply two values, which are Risk-Taking and The Future, Change, and Progress and forget two other values in doing the Manipulative Leadership.

The second outcome concludes that American Manipulative Leadership gives effects towards its subordinate. These effects usually related to how are the subordinates takes the next steps or decision in the future time. The types of Manipulative Leadership would affect not only the society, corporation, institutions, government, but also the individuals, especially its subordinate. When the actions of Manipulative Leadership are already done, and the subordinate find out the truth, the subordinate are going to keep asking him/her self whether the decision he/she already take is the right decision or the wrong decision and the effects of that decision he/she take. The novel Ender's Game can be categorized as a popular culture, because its achievement are really enormous and it became a mass consumption since the mass are really fond of it.

This research is useful for the readers who concerns with American cultural values and the types of leadership uses by the American. The researcher asks the readers to understand more about the American cultural values and request the readers have to be more selective to choose which values to guides them in undergo the daily life. This research also gives the readers the tactics that are commonly uses by manipulative leaders so that readers can avoid this kind of leadership and find out if there are any leaders that use the type of American manipulative leadership.

\section{REFERENCES}

[1] Hochschild, Jennifer L. 1995. Facing Up to the American Dream. New Jersey: Princeton University Press.

[2] Cullen, Jim. 2003. The American Dream: A Short History of an Idea That Shaped a Nation. New York: Oxford University Press.

[3] Rawlings, Nate. 2017. Richard Nixon's Plumbers Top 10 Abuses of Power - TIME. 2011. Retrieved on March 15, 2017 at 16.30 from http://content.time.com/time/specials/packages Larticle/0,28804,2071839 $2071844 \quad 2071846,00$. $\underline{\text { html }}$

[4] Advanced English Dictionary. PC Software. 2017.

[5] Meredith, Robert. 1969. Subverting Culture, The Radical as Teacher. Miami: American Studies, Miami University.

[6] Storey, John. 2008. Cultural Theory and Popular Culture. 5th Ed. New York: Pearson.

[7] Northouse, Peter Guy. 2013. Leadeship: Theory and Practice. Sixth Edition. Los Angeles: SAGE Publications, Inc.

[8] Maxwell, John. 2017. John Maxwell on Leadership: Persuasive or Manipulative?. 2012 Retrieved on May 15, 2017 at 10.45 from http://www.johnmaxwell.com/blog/persuasiveor-manipulative

[9] Teitelbaum, Harry. 1994. How to Write a Thesis. 3rd Ed. New York: Arco Publishing.

[10]Crossman, Ashley. 2017. An Overview of Qualitative Research Methods. 2017 Retrieved on August 3, 2017 at 09.30 from https://www.thoughtco.com/qualitativeresearch-methods-3026555

[11]Bogdan, Robert C., and Sari K.Biklen. 1994. Qualitative Research for Education: An Introduction to Theory and Methods. Boston: Allyn and Bacon.

[12]Card, Orson. Ender's Game. 2013. New York: Tor Publisher.

[13]Roosevelt, Franklin D. State of the Union Address "The Four Freedoms". 1941. Retieved on August 10, 2017 at 13.45 from http://voicesofdemocracy.umd.edu/fdr-thefour-freedoms-speech-text/

[14]Williams, Raymond. 1983. Keywords. London: Fontana. 